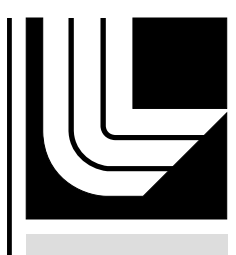

LAW RENCE LIVERMORE N A TIO N A L LABORATORY

\title{
UCRL-TR-210224
}

\section{Climate Modeling using \\ High-Performance Computing}

A. A. Mirin, M. E. Wickett, P. B. Duffy, D. A. Rotman

March 4, 2005 
This document was prepared as an account of work sponsored by an agency of the United States Government. Neither the United States Government nor the University of California nor any of their employees, makes any warranty, express or implied, or assumes any legal liability or responsibility for the accuracy, completeness, or usefulness of any information, apparatus, product, or process disclosed, or represents that its use would not infringe privately owned rights. Reference herein to any specific commercial product, process, or service by trade name, trademark, manufacturer, or otherwise, does not necessarily constitute or imply its endorsement, recommendation, or favoring by the United States Government or the University of California. The views and opinions of authors expressed herein do not necessarily state or reflect those of the United States Government or the University of California, and shall not be used for advertising or product endorsement purposes.

This work was performed under the auspices of the U.S. Department of Energy by University of California, Lawrence Livermore National Laboratory under Contract W-7405-Eng-48. 


\section{Climate Modeling using High-Performance Computing}

The Center for Applied Scientific Computing (CASC) and the LLNL Atmospheric Science Division (ASD) are working together to improve predictions of future climate by applying the best available computational methods and computer resources to this problem. Over the last decade, researchers at the Lawrence Livermore National Laboratory (LLNL) have developed a number of climate models that provide state-ofthe-art simulations on a wide variety of massively parallel computers. We are now developing and applying a second generation of high-performance climate models.

Our collaborators in climate research include the National Center for Atmospheric Research (NCAR), the Geophysical Fluid Dynamics Laboratory (GFDL), the National Aeronautics and Space Administration Goddard Space Flight Center (NASA GSFC), Los Alamos National Laboratory (LANL), Lawrence Berkeley National Laboratory (LBNL), Argonne National Laboratory (ANL), Pacific Northwest National Laboratory (PNNL), Oak Ridge National Laboratory (ORNL), the Scripps Institution of Oceanography (SIO), the Colorado State University, and Naval Research Laboratory Monterey. Some of our main projects are as follows

\section{Collaborative Global Climate Model Development}

As part of LLNL's participation in DOE's Scientific Discovery through Advanced Computing (SciDAC) program, members of CASC and ASD are collaborating with other DOE labs and NCAR in the development of a comprehensive, next-generation global climate model. This model incorporates the most current physics and numerics and capably exploits the latest massively parallel computers. One of LLNL's roles in this collaboration is the scalable parallelization of NASA's finite-volume atmospheric dynamical core. We have implemented multiple two-dimensional domain decompositions, where the different decompositions are connected by high-speed transposes. Additional performance is obtained through shared memory parallelization constructs and one-sided interprocess communication (see Fig. 1). The finite-volume dynamical core is particularly important to atmospheric chemistry simulations, where LLNL has a leading role. 


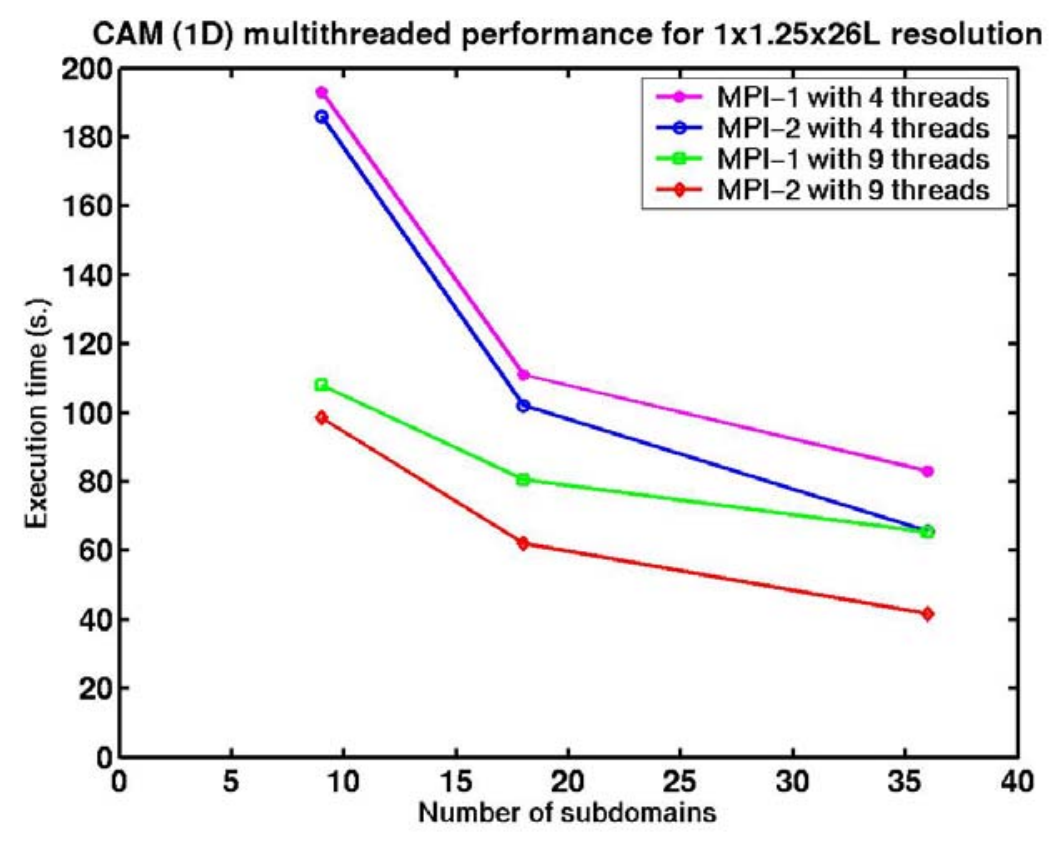

Figure 1. Wall-clock time for the finite-volume dycore at $1^{\circ} \times 1.25^{\circ} \times 26 \mathrm{~L}$ resolution on the SGI Origin as a function of the number of subdomains, using a one-dimensional decomposition. Ordinary MPI communication (MPI-1) is compared with one-sided MPI-2 communication (MPI-2) for both 4 and 9 OpenMP threads per process. MPI-2, which can take advantage of the multithreading in the communications primitives, can yield as much as a $20 \%$ overall reduction in computation time for 4 threads, and a 33\% reduction for 9 threads.

\section{Ocean Carbon Sequestration}

A possible approach to delaying global warming is to "sequester" (store) greenhouse gases in the deep ocean. LLNL leads the numerical simulation effort for the DOE's ocean carbon sequestration research program (see Fig. 2). CASC and ASD are performing model simulations of ocean circulation and biogeochemistry to assess the efficacy and impacts of this approach. In addition, we are developing improved numerical models that will be used to investigate this strategy. 


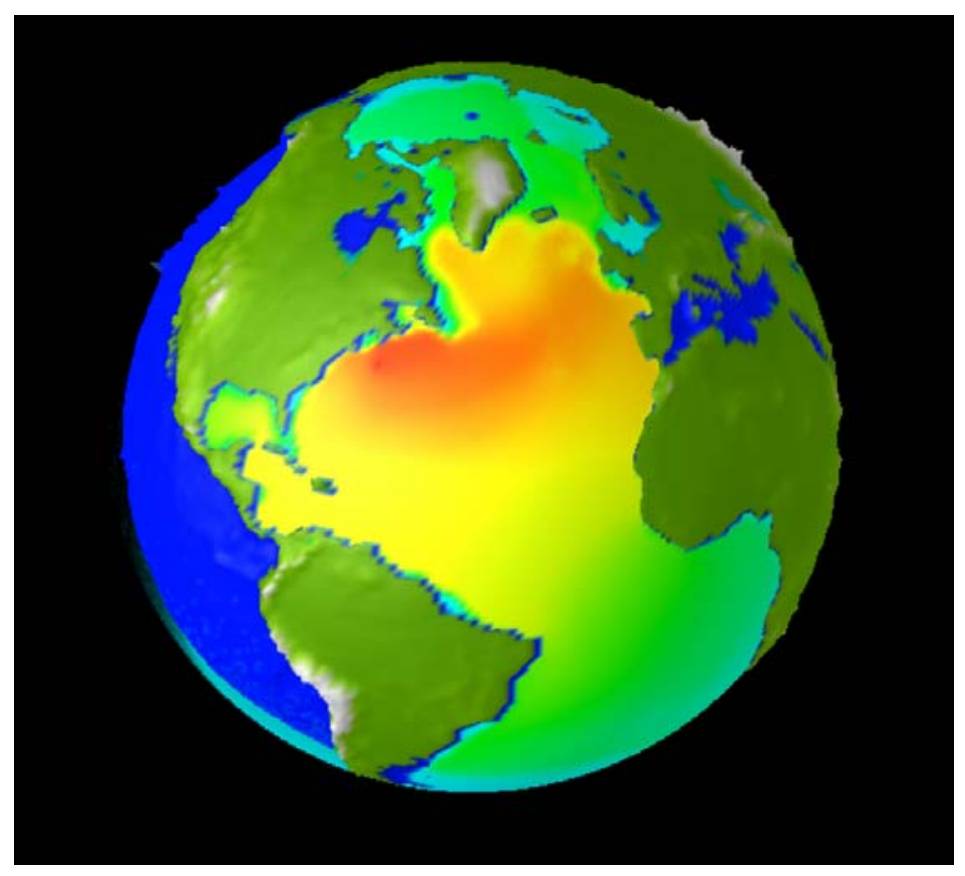

Figure 2. Simulation of ocean carbon dioxide concentration resulting from 100 years of continuous injection at $700 \mathrm{~m}$ depth off the coast of New York City, as computed by the LLNL Ocean General Circulation Model.

\section{Climate Effects of Land-Use Change}

Will growing a forest warm or cool the planet? Preliminary studies indicate that a change from actual vegetation (e.g., farms) back to natural vegetation (e.g., forests) would warm the planet, largely because of albedo effects. In general, the direct climate effects of landuse change (through changes in albedo, surface wetness, surface roughness, etc.) can be of the same magnitude as the carbon storage effects of land-use change. Thus, there is a need to be able to estimate the net climate and carbon consequences of a potential (or actual) land use change. With all of these effects included in LLNL's coupled carbon and climate model, ASD and CASC researchers are simulating potential land use changes. This information will allow more efficient climate and carbon management, help to avoid perverse incentives for climatically counterproductive carbon storage projects, and may suggest new climate and carbon management approaches.

\section{High Resolution Simulations of Global Climate}

Important barriers to more realistic climate simulations have been the relatively coarse resolution used in global climate models, and simplified treatments of subgrid scale processes. Due to the extreme computational demands of global climate simulations, global climate models typically use resolutions of $\sim 300 \mathrm{~km}$. Researchers in ASD and CASC have recently run global climate models at resolutions as fine as $\sim 50 \mathrm{~km}$ (see Fig. 3 ). These are among the highest-resolution global climate simulations ever performed and are made possible by LLNL's and DOE's extraordinary computing resources. As expected, these calculations produce more realistic simulations of many relevant 
quantities. Of particular interest is that the results using fine resolution can be more realistic even on scales that are already resolved by the coarser-resolution models. In addition to simulations of the present climate, we have performed high-resolution simulations of the effects of increased greenhouse gases (global warming). Results of these simulations are being used by a number of research groups in their investigations of regional climate, regional climate change, and the societal impacts of climate change. In order to address limitations of conventional treatments of subgrid scale processes in climate models, particularly vis-à-vis clouds, we are working with a group at the Colorado State University that has developed an exciting and novel approach to representing these processes.

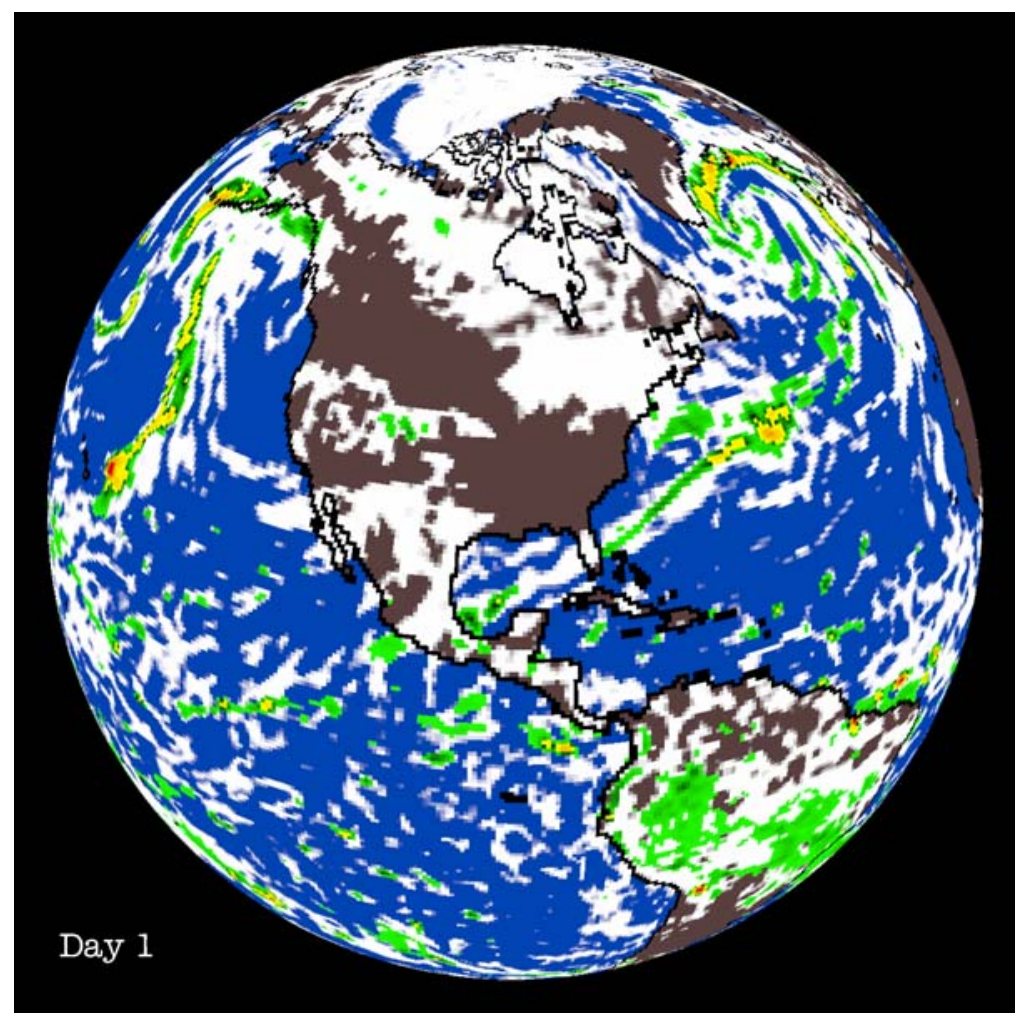

Figure 3. LLNL climate model simulation of precipitation (green) and cloudiness (white). This is a snapshot from a global simulation at $50 \mathrm{~km}$ resolution.

\section{Integrated Climate and Carbon (INCCA)}

Today's three-dimensional climate models predict future climate by specifying future atmospheric concentrations of greenhouse gases and then calculating their radiative and climatic effects. A better approach is to specify greenhouse gas emissions - the quantity that energy policies control - and then calculate future concentrations and future climate. This approach requires incorporating detailed treatments of the carbon cycle and other biogeochemical cycles into climate models. Researchers in CASC and ASD have developed a comprehensive climate/carbon cycle model, which is the first of its type in the United States. This model is being used to evaluate the climatic impact of proposed 
scenarios for greenhouse gas emissions and sequestration. Recent studies include the effects of limited CO2 fertilization on global climate change (see Fig. 4), and the effects of climate sensitivity on carbon cycle feedback. Additionally, the land/biosphere model used in this study (IBIS) has been coupled to the Community Climate System Model Version 3 (CCSM3) as a step toward creating a next-generation integrated climate and carbon cycle model.

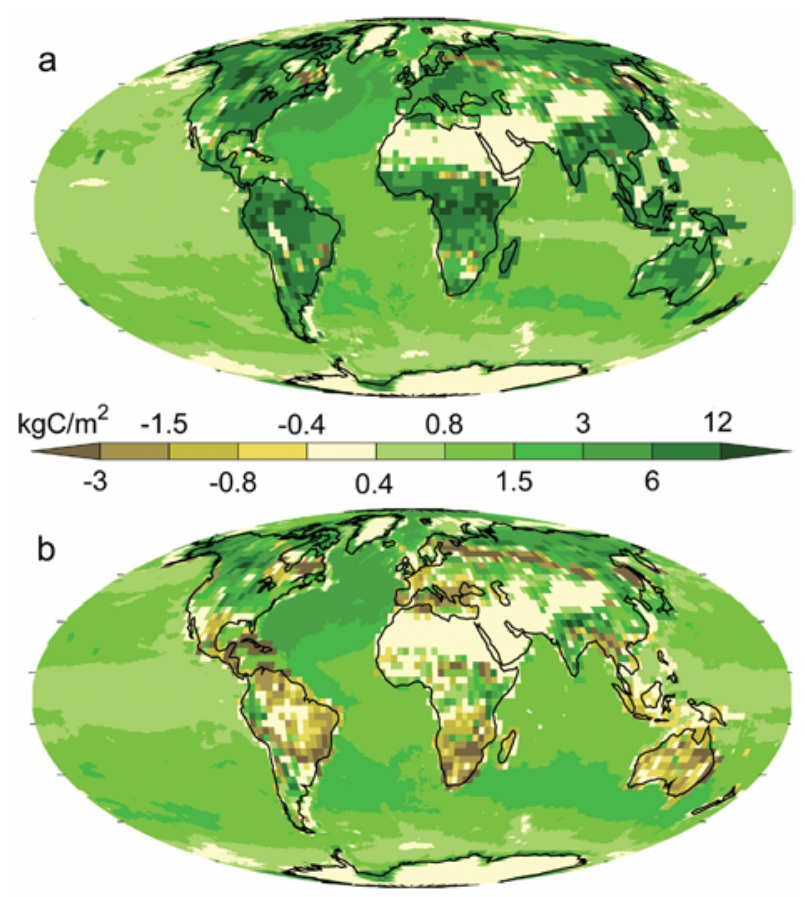

Figure 4. The simulated geography of carbon stored in the earth system over the period from 1870 to 2100 in the a) unlimited fertilization and b) limited fertilization cases (column integrated carbon in $\mathrm{kg} \mathrm{C} / \mathrm{m}^{2}$ ). Anthropogenic carbon is stored primarily in areas of high vegetation productivity and/or cooler climates over land.

\section{Regional Climate Change}

In an effort to study the detection and attribution of regional climate change, researchers in ASD and CASC are performing high-resolution simulations of global climate and using those results to drive even higher-resolution regional scale models (see Fig. 5). The global (CCSM3) and regional (MM5) models have been converted to the Thunder Linux cluster, which is LLNL's most powerful open computing resource. We are attempting to answer the questions, (1) does climate analysis at regional scale afford new insights to climate change detection and impacts, and (2) do uncertainties in forcing matter in our ability to detect regional climate change. In order to evaluate the effects of human activity, simulations both with and without anthropogenic forcing are being carried out. 


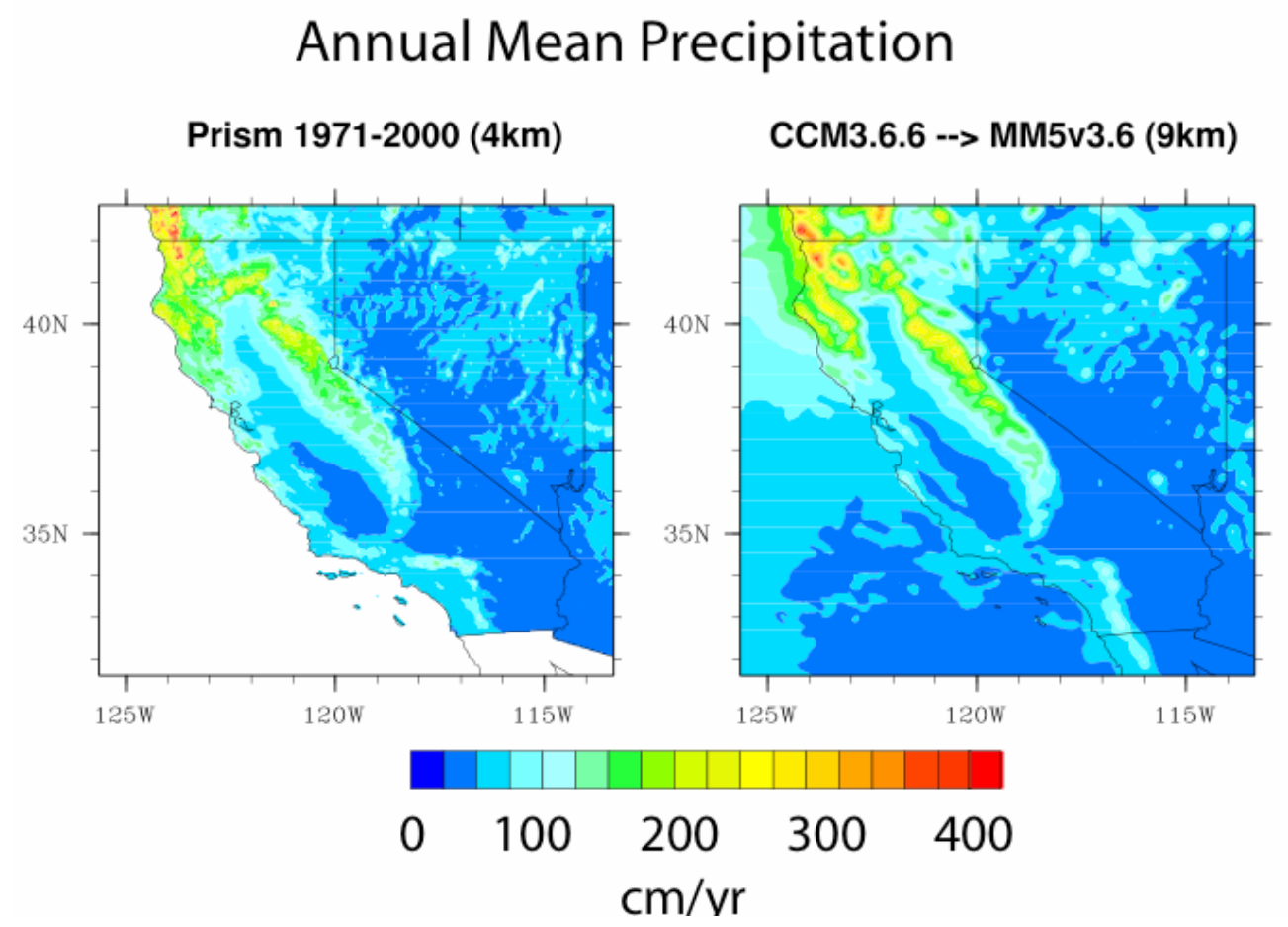

Figure 5. Annual mean precipitation in California and Nevada. The left panel shows an observation-based data set on a $4 \mathrm{~km}$ grid. The right panel shows results of simulations performed at LLNL using a regional climate model at $9 \mathrm{~km}$ resolution nested within a global climate model at $75 \mathrm{~km}$ resolution. The extraordinary fidelity of these simulations results in part from the use of much finer spatial resolutions than are conventionally possible.

\section{Further Information}

For further information, please contact:

(CASC) Art Mirin (mirin@1lnl.gov) or Mike Wickett (wickett1@1lnl.gov) (ASD/E\&E) Phil Duffy (pduffy@llnl.gov) or Doug Rotman (drotman@1lnl.gov)

This work was performed under the auspices of the U.S. Department of Energy by the University of California Lawrence Livermore National Laboratory under contract No. W7405-ENG-48. This is LLNL Report UCRL-TR-210224. 